\title{
Results of the AMS Membership Survey
}

\author{
Pamela L. Stephens \\ National Science Foundation, Washington, DC \\ and Corinne Kazarosian \\ American Meteorological Society, Boston, Massachusetts
}

\section{Introduction}

In recent years, a number of the Society's committees and boards expressed a desire to have information on the characteristics of the present membership that would allow them to better plan activities and carry out their responsibilities. The last formal survey of the Society's membership was conducted by William W. Kellogg in 1975 and published in 1977 (Kellogg 1977). Since that time only basic information on members' affiliations, occupations, and fields of expertise has been collected routinely as part of the annual dues statements, principally for use by AMS headquarters.

In 1989, the AMS Council established an ad hoc committee to develop a questionnaire for a new survey. The members of that committee were selected to be broadly representative of the Society's various constituencies, their perspectives, and concerns. The key objective in conducting the survey was to develop a profile that would show how the membership has changed since 1975 and that also would serve as a baseline for identifying trends in the future. The questionnaire consisted of two parts (see next page). The first part represented the annual request for updated information on affiliations and interests. Part II contained specific questions related to members' education, occupations, salaries, and demographics. The survey committee hoped that members would complete the entire questionnaire, but agreed that even partial responses would have value and should be accepted.

In reporting the results, we have tried, where possible, to compare the 1990 numbers with those of Kellogg's survey. Unfortunately, a copy of the 1975 survey form was not available. Without knowing how the 1975 questions were phrased, it is difficult to judge whether they are comparable to those of the 1990 questionnaire. We also have looked at some statistics that Kellogg did not. Like Kellogg, we have kept our

(C1992 American Meteorological Society analyses simple and have tried to identify where sample sizes are small and results suggestive, but not definitive.

\section{Overall response}

The questionnaire was sent out as part of the 1990 AMS "Annual Statement of Dues \& Subscriptions" in the fall of 1989. By late August 1990, headquarters had received 7460 statements in which members had responded to one or more questions. This represents $72 \%$ of the 10300 AMS members at the time. The response rate was substantially higher than the $54 \%$ response in 1975 and may be attributable to the fact that the survey was combined with the membership dues statement rather than being sent out separately.

In total numbers, the AMS membership has grown in 15 years from 8846 in 1975 to 10300 in 1990. This represents a rather modest growth rate-less than $1 \%$ per year. The organization is international, with about $10 \%$ of our members being located outside of the United States. The number of responses for each category of membership for both 1975 and 1990 is shown in Table 1. We can make only broad comparisons because of the differences in the two surveys. Because the 1990 survey was part of the dues state-

TABLE 1. Distribution of membership by categories. Shown are the number of responses and percentage of total responses for each category, 1975 and 1990.

\begin{tabular}{lcc|rr}
\hline \hline & 1975 & I & 1990 \\
\hline Members & 3423 & $(72 \%)$ & 6200 & $(83 \%)$ \\
Fellows \& honorary & $\overline{613}$ & $(13 \%)$ & 617 & $(8 \%)$ \\
Associate members & 634 & $(11 \%)$ & 298 & $(4 \%)$ \\
Student members & 534 & & \\
No status given & 215 & $(4 \%)$ & &
\end{tabular}


\begin{tabular}{l|l} 
OR AFFILIATION NAME & HOME TEL EPHONE
\end{tabular}

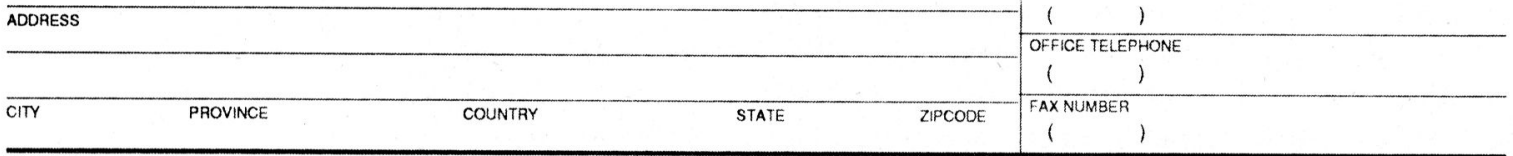

\begin{tabular}{l}
\hline$\square$ 1st \begin{tabular}{l}
\hline 1. AGRICULTURALFOREST METEOROLOGY \\
2. AIR POLLUTION METEOROLOGY \\
3. AIRISEA INTERACTION \\
4. ATMOSPHERIC CHEMISTRY \\
5. ATMOSPHERIC \& CLIMATE OYNAMICS \\
6. ATMOSPHERIC PHYSICS \\
7. ATMOSPHERIC RADIATION
\end{tabular}
\end{tabular}

FIELD OF EXPERTISE: SELECT THREE NUMBERS

PART 2: SURVEY

8. ATMOSPHERIC TURBULENCEDIFFUSION 15. MESOMETEOROLOGY

9. AVIATION METEOROLOGY T. MICROMETEOROLOGY

O. BIOMETEOROLOGY 17. NUMERICAL ANALYSIS \& PREDICTION

22. SEVERE LOCAL STORMS

11. CLIMATOLOGY 18. OCEANOGRAPHY

12. CLOUD PHYSICS/WEATHER MODIFICATION 19. PALEOCLIMATOLOGY

13. HURRICANE/TROP METEOROLOGY 20. RADAR METEOROLOGY

21. REMOTE SENSING

23. SOLARIWINO ENERGY

24. SOLAR TERRESTRIALSOLAR PHYSICS

25. UPPER ATMOSPHERE/AERONOMY

ALL RESPONSES ARE VOLUNTARY. FAILURE TO RESPOND TO A PARTICULAR QUESTION WILL NOT INVALIDATE THE SURVEY. WE URGE YOU TO ASSIST THE AMS BY FILLING OUT THE SURVEY AS COMPLETELY AS POSSIBLE. USING CODES PROVIDED, PLEASE FILL IN BOXES WITH APPROPRIATE RESPONSE.

ASSURANCE OF CONFIDENTIALITY. THE INFORMATION COLLECTED THROUGH THIS SURVEY IS FOR STATISTICAL PURPOSES AND WILL BE RELEASED ONLY IN THE FORM OF STATISTICAL SUMMARIES. THE DATA WILL BE USED TO IDENTIFY SUBSETS OF THE MEMBERSHIP FOR OTHER AMS SURVEYS AT A LATER TIME: HOW-
EVER, AT NO TIME WILL INFORMATION RELATED TO AN INDIVIDUAL BE RELEASED BY THE AMS

\begin{tabular}{|c|c|c|c|c|c|}
\hline \multirow{2}{*}{$\begin{array}{l}\text { YEAR MANOR } \\
\text { BACHELOA'S } \\
\end{array}$} & YEAR MANOR & \multicolumn{3}{|c|}{ EDUCATION - GIVE YEAR(S) CONFERRED AND INDICATE FIELD OF MAJOR } & \multirow{5}{*}{$\begin{array}{l}\text { 19. SOCIAL SGIENCE } \\
\text { 20. STATISTICS } \\
\text { 21. OTHER: (SPECIFY): }\end{array}$} \\
\hline & & \multirow{5}{*}{$\begin{array}{l}\text { 1. ASTRONOMY } \\
\text { 2. ATMOS. SCI./METEOROLOGY } \\
\text { 3. BIOLOGICAL SCIENCE } \\
\text { 4. CHEMISTRY } \\
\text { 5. CLIMATOLOGY } \\
\text { 6. COMPUTER SCIENCE }\end{array}$} & \multirow{5}{*}{$\begin{array}{l}\text { 7. ECONOMICS } \\
\text { 8. ENGINEERING } \\
\text { 9. GEOGRAPHY } \\
\text { 10. GEOLOGY/GEOPHYSICS } \\
\text { 11. HISTORY } \\
\text { 12. HYDROLOGY }\end{array}$} & \multirow{5}{*}{$\begin{array}{l}\text { 13. JOURNALISM } \\
\text { 14. LAW } \\
\text { 15. MATHEMATICS } \\
\text { 16. OCEANOGRAPHY } \\
\text { 17. (OTHER) PHYSICAL SCIENCE } \\
\text { 18. PHYSICS }\end{array}$} & \\
\hline MASTEA'S & & & & & \\
\hline & & & & & \\
\hline DOCTORATE & & & & & \\
\hline & & & & & \\
\hline
\end{tabular}

\begin{tabular}{|c|c|c|c|}
\hline A. STATUS & $\begin{array}{l}\text { 1. EMPLOYED FULL TIME } \\
\text { 2. EMPLOYED PART TIME }\end{array}$ & $\begin{array}{l}\text { 3. GRADUATE STUDENT } \\
\text { 4. UNDERGRADUATE STUDENT }\end{array}$ & $\begin{array}{l}\text { 5. UNEMPLOYED, SEEKING } \\
\text { 6. UNEMPLOYED NOT SEEKING } \\
\text { 7. RETIRED }\end{array}$ \\
\hline
\end{tabular}

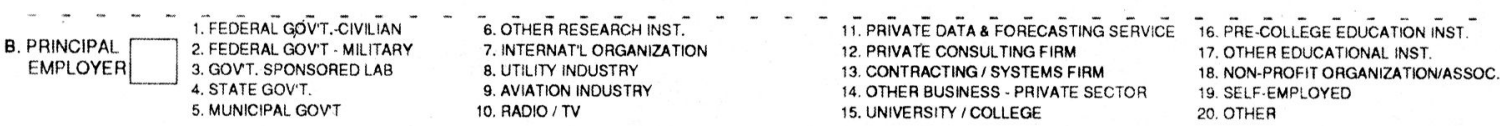
PRINCIPAL EMPLOYER: IF RESPONSE IS 14, 17 OR 20 PLEASE SPECIFY

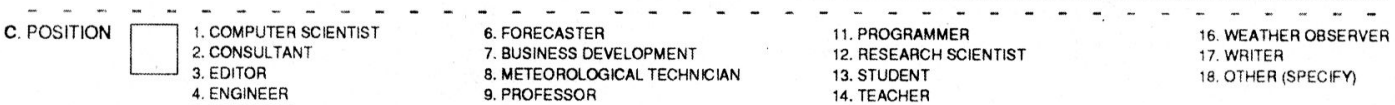
4. ENGINEER 9. PROFESSOR 14. TEACHER

D PRIARÝ - - - - - - - - -

PRIMARY

ACTIVITY 2. APPLIED RESEARCH

10. PROGRAM MANAGER 15. TECHNICIAN

6. COMPUTER APPLLICATIONSS - - - -

7. CONSULTING 12. MGMTIADMIN OF SERVICES
1. OPEATL

$\begin{array}{lll}\text { 3. BASIC RESEARCH } & \text { 8. DESIGN OF EQUIP. PROCESSES } & \text { 13. OPERATL METEOROLOGY FOR } \\ \text { 4. BROADCAST METEOROLOGY } & \text { 9. DEV.MANUF. OF EQUIP. PROD. SERVICES } & \text { 14. REPORT \& TECHNICAL WRITING }\end{array}$ 5. FORENSIC METEOROLOGY 10.MGMT/ADMIN OF EDUCATIONAL PROGRAMS

E. IS YOUR EMPLOYER A U.S. BASED ORGANIZATION? 1. YES 2. NO

F. NUMBER OF YEARS WITH PRESENT EMPLOYER

G. $\square$ DO YOU ENVISION EMPLOYMENT OPPORTUNITIES IN YOUR AREA OF PRIMARY ACTIVITY? 1. INCREASING 2. STAYING THE SAME 3. DECREASING

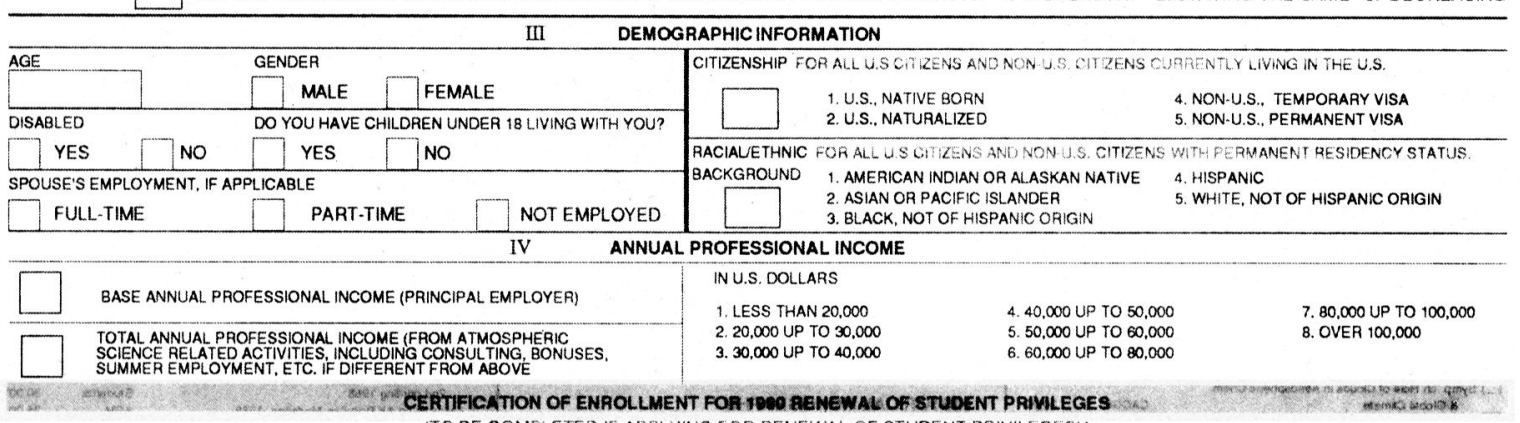

(TO BE COMPLETED IF APPLYING FOR RENEWAL OF STUDENT PRIVILECES)

I CERTIFY THAT

. WHO HAS APPLIED FOR THE RENEWAL OF THE PRIVILEGES OF

STUDENT MEMBERSHIP, IS DULY ENROLLED AS A GRADUATE (UNDERGRADUATE) STUDENT IN RESIDENCE AT: (COLLEGE/UNIVERSITY) ON AT LEAST A HALF-TIME BASIS FROM: $19+19$

SIGNED:

PRINT NAME IS ELIGIBLE FOR, AND IS ELECTED TO, THE GRADE OF MEMBER WITH STUDENT PRIVILEGES 
ment, the membership category for all responses is known. In the 1975 survey, membership category was one of the survey questions. Kellogg reports that 215 participants did not indicate their membership category. The 1975 survey also did not break out fellows and honorary members. It appears that the percentage of students and associate members was higher in 1975. On the other hand, AMS headquarters' records show there were 638 student and 890 associate members, $6 \%$ and $9 \%$ of the total membership, respectively, in 1989.

\section{Characteristics of the membership}

\section{a. Age}

Figure 1 depicts the age distribution of the 1990 membership, a more or less normal distribution. This represents a real change from 1975 when, according to Kellogg, there was a distinct bimodal distribution, with peaks at the 30-34-year and 55-59-year intervals and a minimum at $40-44$ years. While the age distribution in most subgroups of the Society would be similar to Fig. 1, that for broadcast meteorologists is different. As Fig. 2 shows, the distribution highly skewed to the low end, with the mean in the late twenties and early thirties.

\section{b. Gender}

While women are still underrepresented, their percentage in the AMS increased significantly in 15 years, from $2.4 \%$ in 1975 to $7.3 \%$ in 1990 . (There was a $95 \%$ response rate on the question of gender.) Further, as Fig. 3 shows, there are greater numbers of females at the entry level. Women represent $16 \%$ and $10 \%$ of the "under 30" and "30-39" years-of-age groups, respectively.

\section{c. Racial/ethnic background}

Table 2 shows the racial/ethnic backgrounds of AMS members in 1990 and 1975. There were a

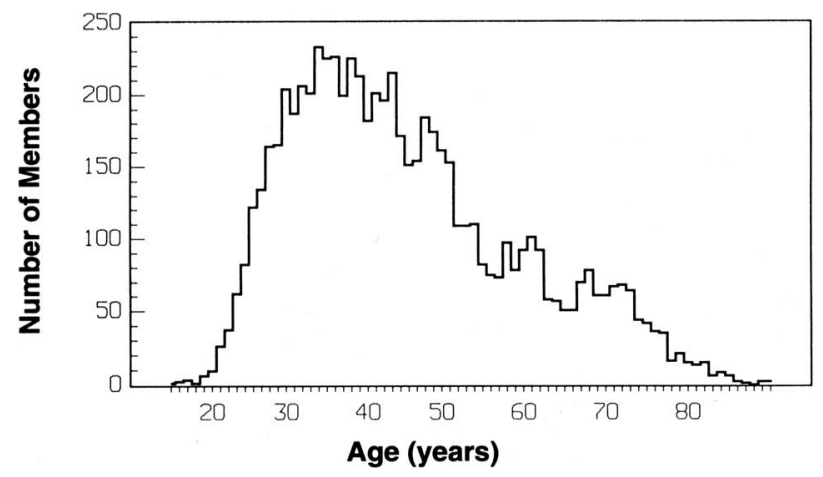

FIG. 1. Age distribution, 1990 survey $($ Total responses $=7381)$

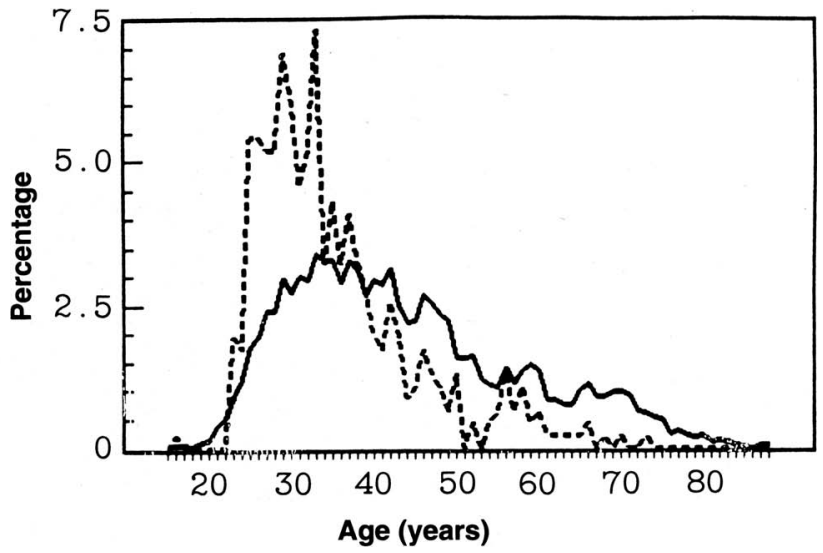

FIG. 2. Percent of members of a particular age. Solid line for the overall membership; dashed line for only broadcast meteorologists.

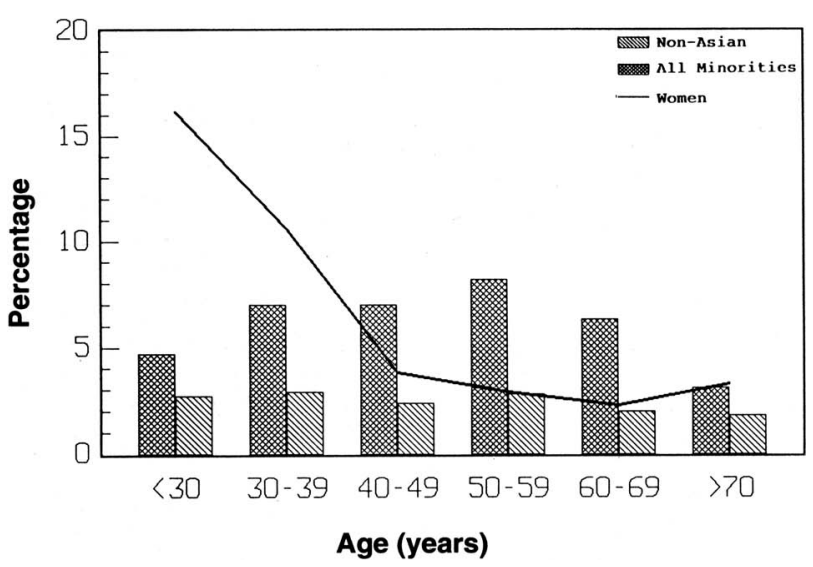

FIG. 3. Percentage of membership composed of women and minorities by age group.

number of survey participants who did not respond $(21 \%)$, although some portion of these are non-U.S. members who were asked not to answer this particular question. Kellogg reported that a number of people objected being asked about their racial or ethnic backgrounds in the 1975 survey.

It is discouraging that the overall percentage of minorities has not increased significantly in 15 years. The numbers suggest that representation of Hispanics has increased threefold; however, the small number of minorities and possible sampling error do not allow us to draw any firm conclusions. Further, as the distribution in Fig. 3 suggests, the percentage of minorities does not differ substantially by age group. Thus, unlike with females, there are no encouraging signs at the entry level.

\section{d. Other demographic information}

In the 1975 survey, information on disabled members apparently was not sought. Of those responding to this question in 1990, $2 \%$ indicated a disability. 
TABLE 2. Distribution of responses by ethnic background in 1975 and 1990.

\begin{tabular}{lrr}
\hline & 1975 & 1990 \\
& & \\
Native Americans & 0.9 & 0.8 \\
Asian/Pacific Islander & 3.2 & 4.1 \\
Black, not Hispanic & 0.5 & 0.6 \\
Hispanic & 0.4 & 1.2 \\
White & 94.0 & 93.3 \\
Other & 1.8 & - \\
\hline
\end{tabular}

Members also were asked whether they had minor children at home or were part of a dual-career family. Of those responding to the first question, $37 \%$ said they have children under 18 years of age living at home. Of those responding about a spouse's employment, $39 \%$ had a spouse who is employed full time, $22 \%$ had spouses employed part time, and $39 \%$ had spouses who are not employed.

\section{Education}

Responses to the questions on the highest level of education must be interpreted with care because the 1990 questionnaire did not include a category for those with less than a college degree. Thus, we are uncertain as to what portion of the $14 \%$ who did not provide information in this category do not hold a college degree and how many simply did not answer the question. The percentages for each response category are shown in Table 3.

The 1975 results were presented by highest degree obtained: $10.2 \%$ had less than a college degree; $24.2 \%$ held a B.A./B.S.; $37.5 \%$, an M.A./M.S.; and $28.2 \%$, a Ph.D. Assuming all holders of doctorates and master's degrees earned a bachelor's degree, then almost 90\% held B.A./B.S. degrees in 1975. [Again, a direct comparison with Kellogg's results is not possible because we lack information on those without a college-level degree in the 1990 survey.]

TABLE 3. Percentage of members holding a particular level of degree, 1990.

\begin{tabular}{lr} 
Degree & $\%$ \\
B.A./B.S. & 86 \\
2nd B.A./B.S. & 6 \\
M.A./M.S. & 57 \\
2nd M.A./M.S. & 4 \\
Ph.D. & 30 \\
2nd Ph.D. & $<1$ \\
\hline
\end{tabular}

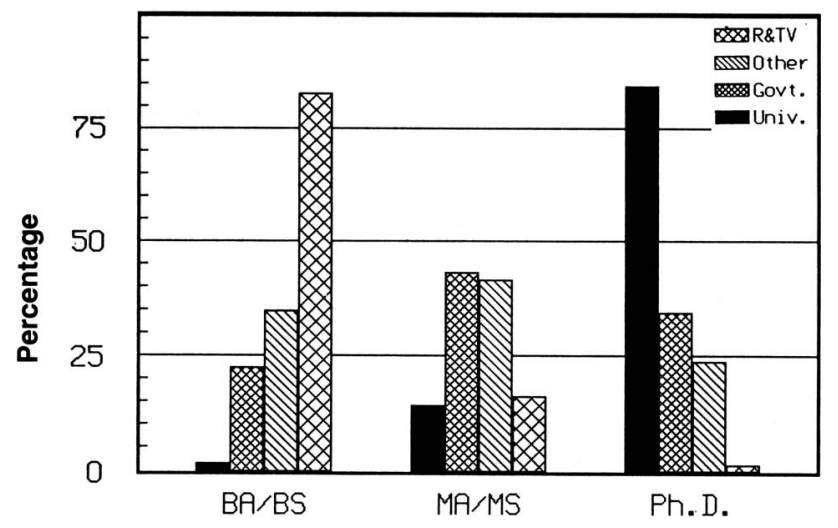

FIG. 4. Percentage of highest degree earned within employment sector.

It is perhaps more interesting to look at how the degrees vary with other parameters. Figure 4 shows how degrees are distributed within broad employment sectors. It is no surprise to find that university employees overwhelmingly hold Ph.D.'s. Kellogg indicated that $79 \%$ of the university people held Ph.D.'s in 1975, and the portion in 1990 was only slightly higher. Broadcast meteorologists generally hold bachelor's degrees, though often in majors other than the atmospheric sciences. In the government and other sectors, there is a range of degrees. For the purposes of these analyses, the government sector included both military and civilian, as well as federal, state, and local; private sector included industry groups to the selfemployed.

Whatever the level of degree, it goes without saying that atmospheric science is the predominant discipline $-42 \%$ of the B.A./B.S. holders, $61 \%$ of the M.A./ M.S. holders, and $53 \%$ at the Ph.D. level. Even so, there is a broad spectrum of disciplines represented among the members and variation in the popularity of disciplines according to degree level. With the first degree, physics (15\%), math (10\%), and engineering $(8 \%)$ are the most common disciplines after atmospheric sciences. At the master's level, the order is physics $(7 \%)$, engineering ( $5 \%)$, and oceanography (4\%). At the doctorate level, oceanography (10\%) ranks higher than physics (8\%) and engineering (6\%). The remaining degrees cover a very broad spectrum, including music education, animal science, theology, and physical education.

\section{Fields of expertise}

When the questionnaire was designed, the survey committee tried to combine several categories under the "Fields of Expertise" section of the old dues state 


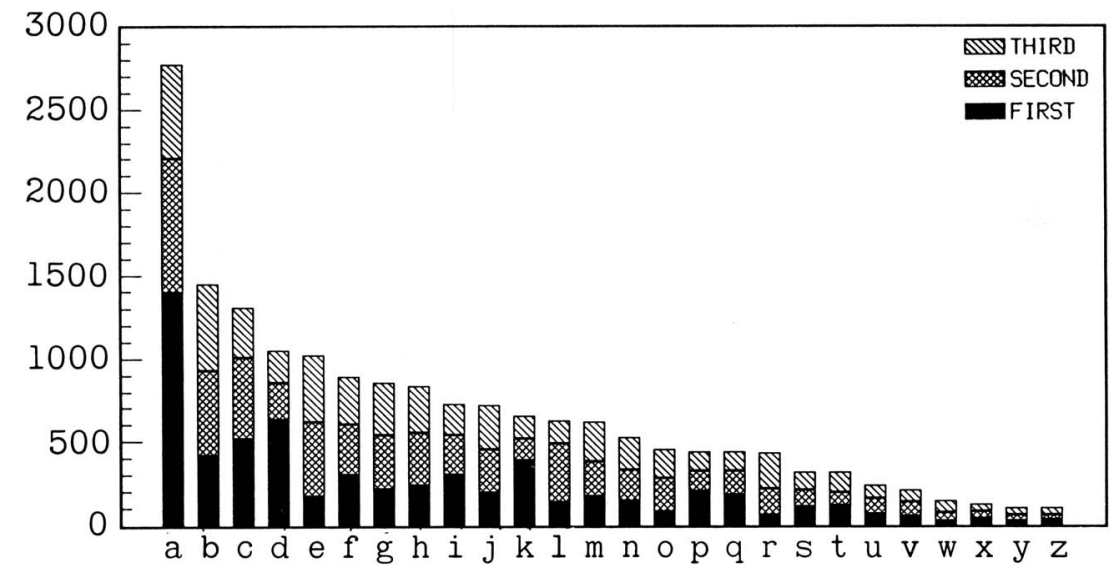

FIG. 5. Fields of expertise-combined total of 1st, 2nd, and 3rd areas of choice.

$a=$ Weather analysis and prediction
$b=$ Climatology
$c=$ Aviation meteorology
$d=$ Air pollution
$e=$ Severe storms
$f=$ Remote sensing
$g=$ Mesometeorology
$h=$ Numerical analysis \& prediction
$i=$ Atmospheric and climate dynamics
$j=$ Hurricane \& tropical meteorology
$k=$ Oceanography
I $=$ Turbulence \& diffusion
$m=$ Radar meteorology

ately in the last 15 years: in 1975 , $3.6 \%$ of the members indicated physical oceanography was their primary professional interest; in 1990 , the percentage was up to $5.7 \%$.

Initially we were puzzled by the large number of people who chose "other," especially for their primary area of expertise. We compiled a list of "other" responses where they had been specified. It did not take long to realize that many see their own fields embodying unique expertise. This is especially true of the broadcast meteorologists-15\% of those who identified themselves as broadcastmeteorologists elsewhere in the survey specified "broadcast meteorology" as their area of expertise. Other frequently listed expertise areas included "satellite meteorology," "computer science," and "instrumentation."

Another interesting analysis is to see how the distribution of education level varies within areas of expertise. Figure 6 shows, for each of 12 expertise areas, the percentage ments. The intent was to reduce the total number of choices to a more manageable number. The results of the survey indicate that, in some cases, members did not readily identify their fields among the new broader categories.

Members could identify and rank up to three areas of expertise-about $10 \%$ did not identify even one, $17 \%$ did not specify a second, and $25 \%$ did not indicate a third. Figure 5 shows, for each area of expertise, the combined total of first, second, and third areas of expertise. "Weather analysis and prediction" is the most common field, both as a primary area of expertise and overall. This is followed by "climatology," "aviation meteorology," "air pollution," and "severe local storms." We note that, although ranking second in the overall numbers, "climatology" was as likely to be an individual's second or third area as the primary one. This is clearer when one looks at the order of primary areas of expertise. As noted above, "weather analysis and prediction" ranks first, representing $21 \%$ of those responding to this question. However, as Fig. 5 shows, the order changes thereafter with "air pollution" and "aviation meteorology" outranking "climatology," which is fourth. The next most common expertise is "oceanography." The number of oceanographers has grown in absolute number and proportion- of members in a given field who hold a bachelor's, master's, or Ph.D. degree. In all fields, $90 \%-95 \%$ of people hold bachelor's degrees, whereas the percentage of those with a Ph.D. varies considerably according to expertise. Among dynamicists and oceanographers, there are more than $75 \%$ and $65 \%$, respectively, who hold doctorates. We postulate that people working in these areas are likely to be basic researchers at universities or research labs. It appears that a Ph.D. is less likely to be required of those in operational areas such as aviation or weather analysis and prediction.

\section{Current employment}

\section{a. Employment status}

Table 4 shows the distribution for the members' employment status in 1990. Looking at the student members, we find there were a total of 409 survey responses from graduates and undergraduates- $5 \%$ and $1 \%$, respectively - but only 298 survey responders have student membership status (Table 1). There are several possible reasons for this apparent discrepancy; for example, graduate students may qualify for and choose full member status. 


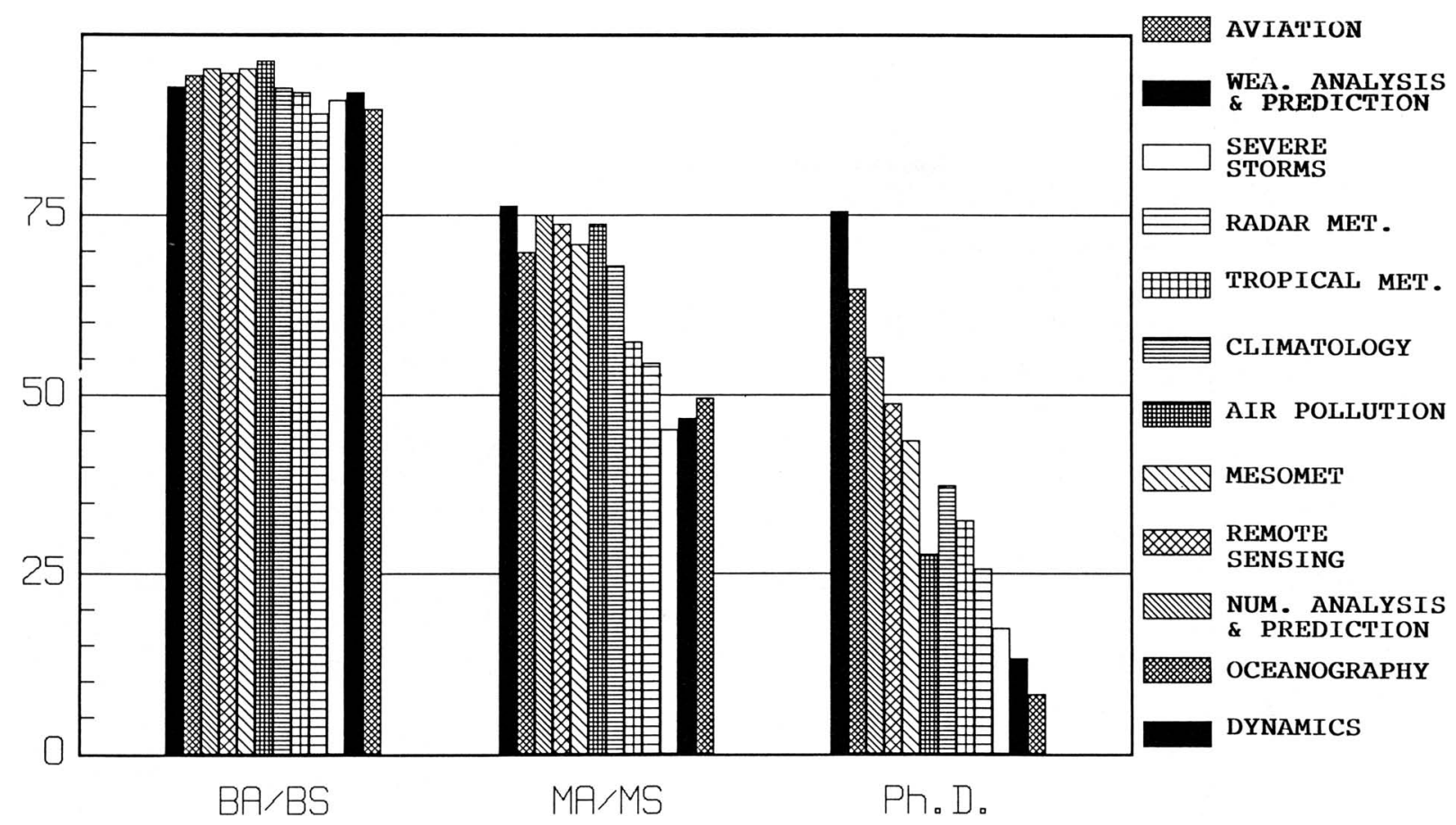

FIG. 6. Percentage of degrees earned within each area of expertise.

TABLE 4. Employment status, 1990.
Employed full time

Employed part time

Graduate student

Undergraduate student

Unemployed, seeking employment

Unemployed, not seeking employment

Retired

TABle 5. Principal employer, 1990.

Federal government

Military

Government-sponsored lab

State government

Municipal government

Other research institution

International organization

Utility industry

Aviation industry

Radio/television

Private data \& forecasting service

Private consulting firm

Contracting/systems firm

Other business-private sector

University/college

Precollege education

Other educational institution

Nonprofit organization/association

Self-employed

Other
$24.7 \%$

6.7

3.6

2.9

0.9

1.6

0.5

1.2

1.5

8.1

2.2

8.1

4.2

4.6

22.4

0.6

0.3

0.9

3.2

1.8
We can compare the 1990 figures to the 1975 results. In 1975, graduate students represented $6 \%$ of the members, and undergraduates were nearly $3 \%$. Those who were unemployed and seeking employment was slightly higher at $2 \%$. The differences be tween 1975 and 1990 in the above categories may not be significant given the small numbers and different survey response rates. One notable change is in the number of retired members. In 15 years, the retirees have gone from less than $5 \%$ to over $9 \%$. There are a number of possible explanations, but the most likely is found in the last survey. Recall that Kellogg mentions the bimodal age distribution in 1975, with one peak being the 55-59 age group made up of World War II meteorologists. Those individuals would now

TABLE 6. Comparison of "Principal employer" responses, 1975 and 1990.

\begin{tabular}{lcc}
\hline & 1975 & 1990 \\
& & \\
Federal government & $30.9 \%$ & $28.3 \%$ \\
Military & 11.6 & 6.7 \\
State and local government & 3.8 & 3.8 \\
University/college & 27.1 & 22.4 \\
Industry & 9.9 & 11.5 \\
Private consulting/self-employed & 7.0 & 13.5 \\
Nonprofit & 4.1 & 0.9 \\
School & 2.0 & 0.6 \\
Broadcast meteorology & & 8.1 \\
Other & 3.6 & 40.2 \\
& &
\end{tabular}




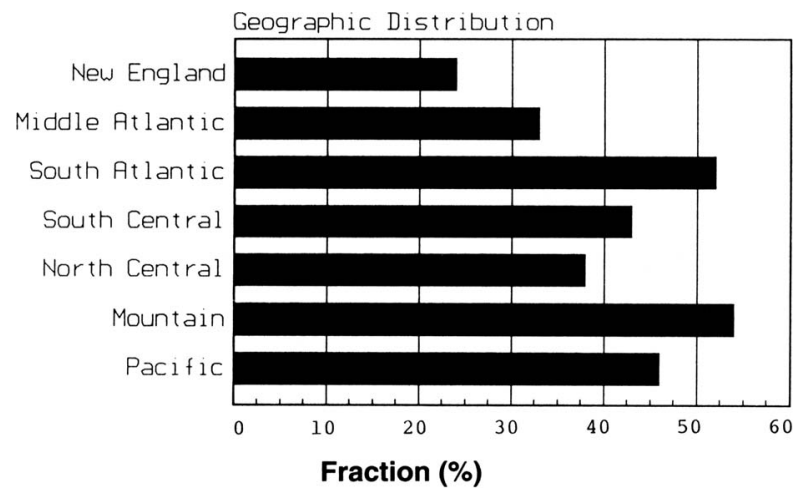

FIG. 7a. Fraction employed by government.

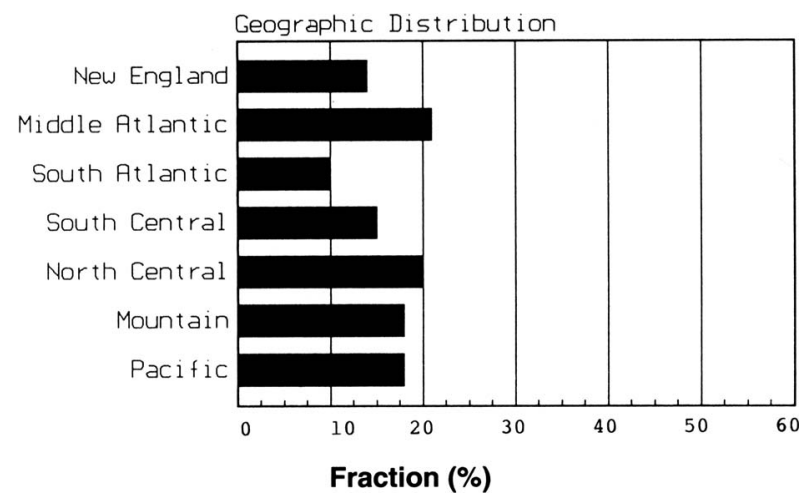

FIG. 7b. Fraction employed by universities.

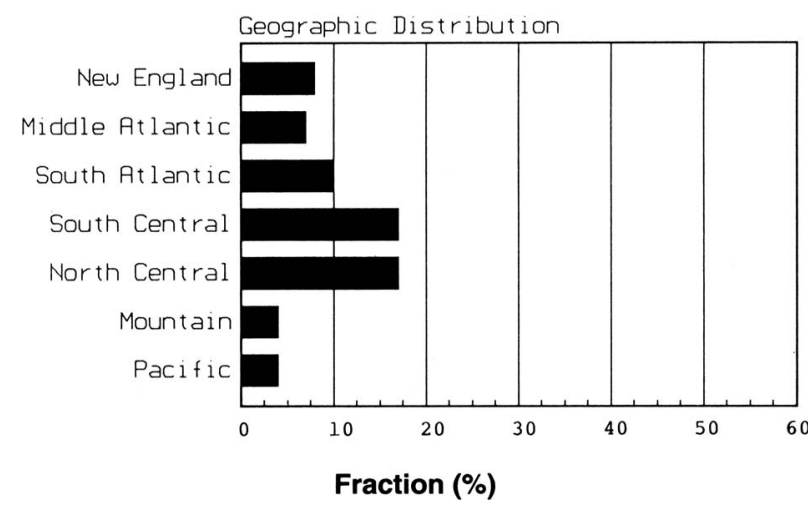

FIG. 7c. Fraction employed in broadcasting.

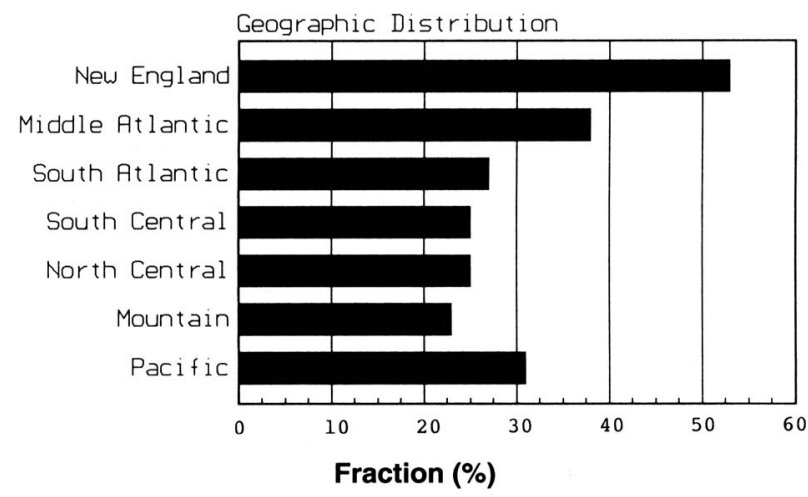

FIG. 7d. Fraction employed in private sector. be 70-75 years old. Looking at the age distribution for survey retirees, we find that, indeed, many of the retirees are in this age range.

\section{b. Principal employer}

In 1990, there were more choices for the principal organizational affiliation than in the 1975 survey. Table 5 shows the total percentage for each category of those responding to this question. For purposes of comparison we have aggregated the current categories to what we hope parallels Kellogg's categories. Some of the combinations are strictly our "best guess" (e.g., broadcast meteorologists apparently were not counted separately in the original survey). Table 6 shows the comparison of the 1975 and 1990 results.

The important thing to notice in Table 6 is the tremendous growth of the private sector relative to the government and educational sectors of the Society. If we consider the private sector to consist of those employed in industry, consulting, broadcast meteorology, and the self-employed, then the private sector has grown from about $17 \%$ in 1975 to over $33 \%$ in 1990 , nearly doubling.

We can also look at employment geographically. Figure 7 shows such an analysis for the employment sector distribution according to geographic region, where a region is defined in the standard way. ${ }^{1}$ In this figure, the percentages of people working (full-time only) in the four broad sectors-government, university, private/industry, and broadcast-are shown for each of the seven geographical regions. The private sector dominates employment in New England; the government employs most of our members who live in the South Atlantic and Mountain regions; and broadcast meteorologists are better represented in the central regions. The portion of people employed by universities is fairly consistent from region to region.

1 The geographic regions are defined as follows: New EnglandME, NH, VT, MA, RI, CT; Middle Atlantic-NY, NJ, PA; South Atlantic-DE, MD, DC, VA, WV, NC, SC, GA, FL; South CentralKY, TN, AL, MS, AR, LA, OK, TX; North Central-OH, IN, IL, MI, WI, MN, IA, MO, ND, SD, NE, KS; Mountain-MT, ID, WY, CO, NM, AZ, UT, NV; and Pacific-WA, OR, CA, AK, HI.

TABLE 7. Most common responses to "Professional position," 1990.

$\begin{array}{lc}\text { Research scientists } & 22 \% \\ \text { Forecasters } & 15 \\ \text { Professors } & 13 \\ \text { Program managers } & 8 \\ \text { Executives } & 7 \\ \text { Consultants } & 7 \\ \text { Students } & 5\end{array}$


TABLE 8. Most common responses to "Primary activity," 1990.

$\begin{array}{lc}\text { Basic research } & 17 \% \\ \text { Applied research } & 12 \\ \text { Management/administration } & 11 \\ \text { Applied meteorology } & 11 \\ \text { Operational forecasting } & 10 \\ \text { Broadcast meteorology } & 8 \\ \text { Teaching } & 8 \\ \text { Consulting } & 6 \\ \text { Computer applications } & 6\end{array}$

\section{c. Professional position}

Table 7 shows the categories with the highest percentage of responses to the question on "professional position." In light of some of the responses, the question probably could have been better posed. Some $12 \%$ of the participants chose the response of "other." Among those, a good number identified themselves as either "broadcast meteorologists" or "meteorologists" for lack of an "appropriate" category. If the survey data are to be useful and easily interpreted, questions relating to job characteristics in future surveys will have to be modified.

Despite the above, important clues about the membership do emerge. For instance, 13\% identified themselves as professors. Since about $22 \%$ of the members are employed by universities, $9 \%$ must be either in nonteaching positions or consider themselves primarily research scientists. This is similar to
1975 , where $27 \%$ were at universities and colleges, but only $11 \%$ identified college teaching as their principal type of work.

\section{d. Primary activity}

Another way of looking at the type of work people do is to ask what they identify as their principal activity. Table 8 presents the results for the most common responses. At first glance, it would seem that these figures do not agree with the professional position information. However, one must take into account factors such as that research scientists may be involved in either basic or applied research, professors may do more research than teaching, and so forth.

\section{e. Numbers of years with employer}

The statistics show that about $50 \%$ of the members have been with their employers 6 years or less; $65 \%$ have been with employers for 10 years or less. On the other end of the spectrum, we find that almost $8 \%$ have been with their employer for 25 years or more.

\section{Opportunities within area of primary activity}

The survey committee felt some valuable insights might be gained by asking members how they viewed employment opportunities in their areas. Overall, $54 \%$ of the respondents anticipate job opportunities in their fields remaining the same, $33 \%$ view job opportunities as increasing, and only $10 \%$ see them decreasing.

This question is much more interesting when the response is broken out by employment sector. It is noteworthy that the greatest optimism was in the private sector (see Table 9). The result is similar to 1975 , where the greatest potential for expansion in opportunities was seen in the private sector (35\%). The outlook for employment opportunities at universities and colleges was also reviewed by Vincent (1991), where $56 \%$ saw no change in opportunities and $39 \%$ saw opportunities increasing.

\section{Salaries}

We were pleased that over $80 \%$ of the participants completed the section on income. The Society is asked often about salary statistics, especially by

FIG. 8. Percentage in each income range by employment sector. 


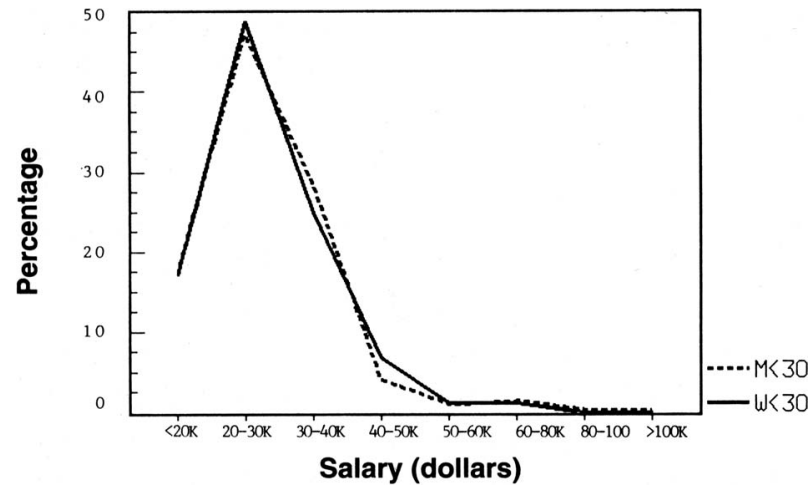

Fig. 9a. Percentage in each salary range for women and men under 30 years of age.

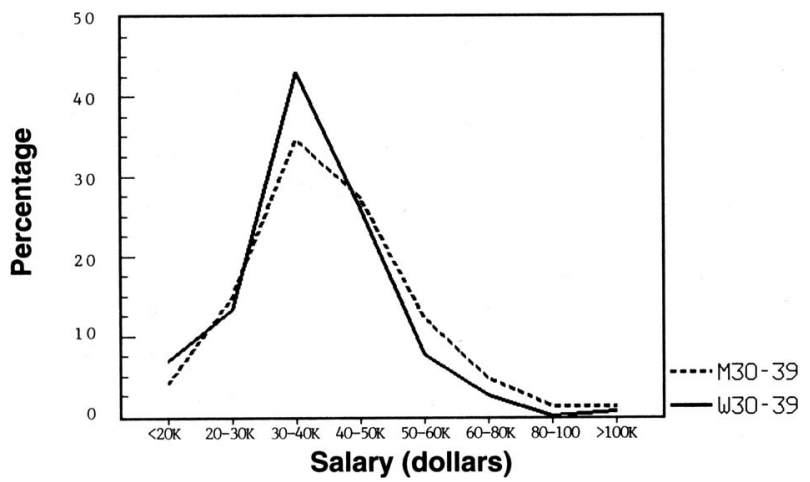

Fig. 9b. Percentage in each salary range for women and men 30-39 years of age.

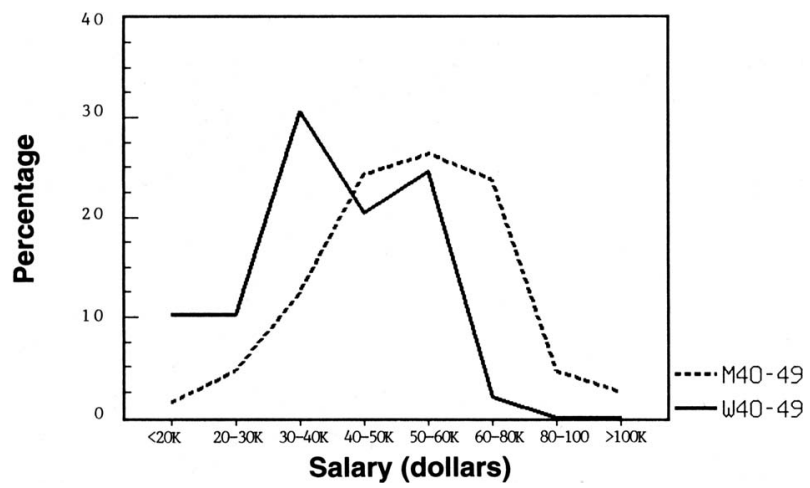

Fig. 9c. Percentage in each salary range for women and men 4049 years of age.

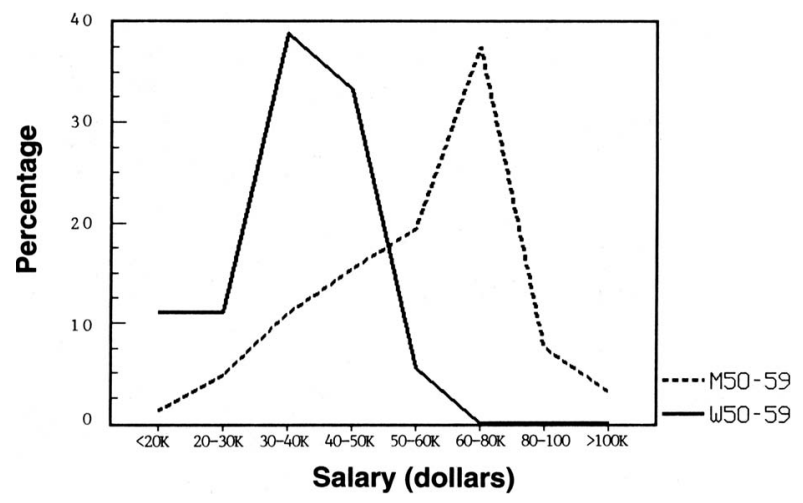

Fig. 9d. Percentage in each salary range for women and men 50-59 years of age.
TABLE 9. Employment Opportunities by sector, 1990.

\begin{tabular}{lccc}
\hline Sector & $\begin{array}{c}\text { Increasing } \\
\text { (\%) }\end{array}$ & $\begin{array}{c}\text { Decreasing } \\
\text { (\%) }\end{array}$ & $\begin{array}{c}\text { Same } \\
\text { (\%) }\end{array}$ \\
\hline & & & \\
Government & 30 & 14 & 55 \\
University & 38 & 5 & 56 \\
Broadcast meteorology & 20 & 9 & 71 \\
Private & 44 & 8 & 48 \\
& & & \\
\hline
\end{tabular}

young people who are considering careers in the atmospheric and related sciences.

The distribution of annual professional income is most interesting when examined in relation to other characteristics. The statistics used to compile Figs. 8 and 9 included only full-time employees. Fig. 8 shows how salary varies with employment sector. Those in the government sector do fairly well until the salary cap is reached. The highest salaries are earned in broadcasting and the private/industry sectors.

When we looked at how salaries vary with gender, we found that the survey response reflects the problems of the labor market in general. Figure $9 a-d$ shows by age group the percentage of men and women who fall into a given salary range. Men and women under 30 years of age make comparable salaries. Between 30 and 40 , men do slightly better. The salary gap widens considerably with age until in the 50-year age group, in which men appear to make at least $\$ 10,000$ a year more than their female counterparts. This issue was also discussed by Vincent (1991).

\section{Summary and recommendations}

The 1990 AMS membership survey has provided an interesting and useful profile of the members. There are changes that are taking place in the nature and makeup of the Society, such as the expansion of the private-sector membership, which will have to be taken into account as we plan future activities. There is much more that can be done with the survey statistics, and some of the Society's groups (for instance, the planning commission) already have made use of the survey results.

It will be important to continue to conduct these surveys on a regular basis. The survey committee members recommend that the survey be repeated, at a minimum, every 3 to 5 years. It may be that certain questions should be requested annually or biennially, 
while every 5 years or so may be frequent enough for others.

The questionnaire itself can be improved. The committee has compiled a list of suggestions that we hope will be incorporated into the next survey. Of course, it will be important that the form not differ too radically, so that the 1990 statistics can serve as the baseline for future surveys. It would be helpful to have comments from those who participated in the survey as to what improvements or clarifications they believe should be made.

Acknowledgments. The survey committee members-Alan Eustis, Rachel Pinker, Paul Try, and Ed Young-devoted much time, energy, and thought to designing the questionnaire. The support from AMS headquarters, from the thoughtful guidance of the execu- tive director and others to those who took on the laborious task of data entry, has been superb. Special thanks go to Keith Orville for his help with the statistical analyses. William Kellogg provided valuable and much appreciated guidance and critical review. Finally, we appreciate the advice and suggestions that came from the review committee and members of the AMS Executive Committee.

\section{References}

Kellogg, W.W., 1977: Results of the AMS questionnaire of 1975. Bull. Amer. Meteor. Soc., 58, 39-67.

Vincent, D.G., 1991: Seventh meeting of the heads and chairmen of departments of atmospheric science-A summary. Bull. Amer. Meteor. Soc., 72, 983-1000.

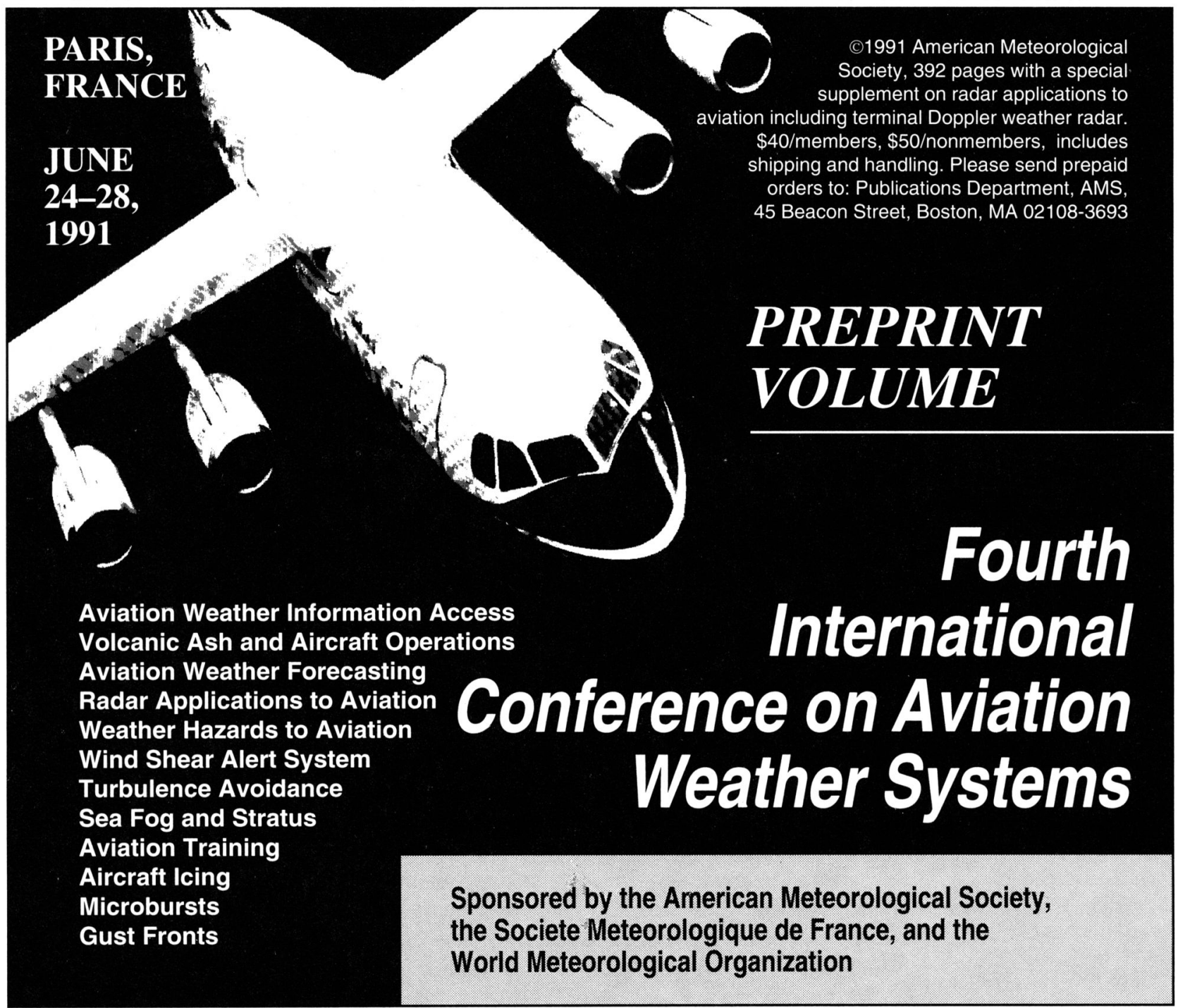

